\title{
Gambaran Fungsi Kognitif Pasien Pasca Stroke
}

\author{
Reinaldi O. Boletimi, ${ }^{1}$ Mieke A. H. N. Kembuan, ${ }^{2}$ Junita M. Pertiwi ${ }^{2}$
}

\author{
${ }^{1}$ Program Studi Pendidikan Dokter Fakultas Kedokteran Universitas Sam Ratulangi, Manado, \\ Sulawesi Utara, Indonesia \\ ${ }^{2}$ Bagian Neurologi Fakultas Kedokteran Universitas Sam Ratulangi, Manado, Sulawesi Utara, \\ Indonesia \\ Email: reinaldi.b.10@gmail.com
}

\begin{abstract}
Stroke or brain attack occurs directly and its incidence is still very high until now. It is reported that two-thirds of stroke patients suffered from cognitive impairment leading to dementia within three months after stroke that can interfere with one's daily activities if left untreated. This study was aimed to obtain the description of cognitive function in post-stroke patients. This was a literature review study using three databases, as follows: Goggle Scholar, Pubmed, and Clinical Key, and the keywords were cognitive impairment, cognitive decline, post-stroke, and MoCA. There were 10 literatures that met the inclusion and exclusion criteria. The results showed that many post-stroke patients showed cognitive function decline in the visuospatial/executive, memory, language, attention, and abstract domains. Cognitive impairment occured mostly in male patients, age 60 years and over, low education, ischemic stroke, left hemisphere lesion, with a history of hypertension. In conclusion, there is a relationship between post-stroke cognitive impairment and the location of lesion, age, and education level, albeit, there was no relationship between the cognitive impairment and gender as well as diabetes mellitus.
\end{abstract}

Keywords: cognitive impairment, post-stroke, MoCA

\begin{abstract}
Abstrak: Stroke menyerang otak secara langsung dengan angka kejadian yang masih sangat tinggi sampai saat ini. Dua pertiga pasien stroke dilaporkan mengalami gangguan fungsi kognitif yang berujung pada demensia dalam tiga bulan pasca stroke serta dapat mengganggu aktivitas sehari-hari bila dibiarkan. Penelitian ini bertujuan untuk mendapatkan gambaran fungsi kognitif pasien pasca stroke. Jenis penelitian ialah literature review, dengan pencarian literatur pada tiga database yaitu Goggle Scholar, Pubmed, dan Clinical Key. Kata kunci yang digunakan ialah penurunan fungsi kognitif, pasca stroke, dan MoCA. Hasil seleksi mendapatkan 10 literatur yang memenuhi kriteria inklusi dan eksklusi. Hasil penelitian menunjukkan bahwa pada pasien pasca stroke sering terjadi penurunan fungsi kognitif dengan domain visuospasial/eksekutif, memori, bahasa, atensi, dan abstrak yang paling sering terganggu. Penurunan fungsi kognitif banyak ditemukan pada pasien laki-laki, usia 60 tahun ke atas, jenjang pendidikan rendah, stroke iskemik, lesi hemisfer kiri, dengan riwayat hipertensi. Simpulan penelitian ini ialah adanya hubungan antara penurunan fungsi kognitif dengan lokasi lesi, usia, dan jenjang pendidikan namun tidak terdapat hubungan dengan jenis kelamin dan diabetes melitus.
\end{abstract}

Kata kunci: gangguan kognitif, pasca stroke, MoCA

\section{PENDAHULUAN}

Stroke merupakan penyakit yang menyerang otak secara langsung. Menurut WHO, stroke adalah penyakit dengan tanda klinis berupa gangguan fokal atau global fungsi serebral yang berkembang pesat, berlangsung 24 jam atau lebih akibat gangguan vaskularisasi otak. ${ }^{1}$

Menurut data dari World Stroke Organization terdapat lebih dari 13,7 juta kasus 
stroke baru setiap tahunnya. Secara global, satu dari empat orang dengan usia di atas 25 tahun mengalami stroke. Angka kematian akibat stroke dilaporkan sebanyak 5,5 juta kasus. ${ }^{2}$ Kejadian stroke di Indonesia diperkirakan sekitar 2,1 juta orang dengan angka kejadian terbanyak pada kelompok usia 5564 tahun yaitu sebesar 33,3\%. ${ }^{3}$

Stroke dapat menyebabkan kecacatan fungsi sensorik, motorik, bahkan fungsi kognitif, bila dibiarkan. Hal ini dapat memengaruhi kualitas hidup pasien dan secara tidak langsung akan memengaruhi prognosis pasien. ${ }^{4}$ Fungsi kognitif adalah kemampuan intelektual yang meliputi pemahaman dan penggunaan bahasa, persepsi dan penggunaan kemampuan berhitung, attention (proses informasi), memori, dan fungsi eksekutif seperti merencanakan, problem solving, dan self-monitoring. Gangguan pada fungsi kognitif bila dibiarkan akan mengganggu aktivitas sehari-hari. ${ }^{4}$ Sebagai contoh ialah gangguan memori yang sering terjadi pada pasien pasca stroke. ${ }^{5}$

Dua pertiga dari penderita stroke yang selamat mengalami gangguan kognitif atau penurunan sesudah serangan stroke. Hampir sepertiga mengalami demensia dalam 3 bulan pasca stroke. Sekitar $25 \%$ penderita stroke yang bertahan hidup didiagnosis demensia setelah 12 bulan serangan stroke ${ }^{6,7}$ Hasil penelitian yang dilakukan di Poliklinik Saraf RSUD Arifin Achmad Provinsi Riau pada bulan NovemberDesember tahun 2015 menunjukkan bahwa pada distribusi frekuensi fungsi kognitif pada pasien pasca stroke, sebagian besar mengalami gangguan fungsi kognitif, yaitu sebanyak 38 orang $(92,68 \%)$ dari 41 responden. ${ }^{8}$ Demikian pula penelitian yang dilakukan oleh Paparang et $\mathrm{al}^{9}$ di Poliklinik Saraf RSUP Prof. Dr. R. D. Kandou Manado dilaporkan bahwa sebagian besar pasien rawat jalan pada periode November 2012 dengan riwayat stroke mengalami gangguan fungsi kognitif baik yang ringan $(45,10 \%)$ maupun yang sedang $(17,65 \%){ }^{9}$

Tingginya angka kejadian stroke serta pengaruhnya terhadap fungsi kognitif mendorong penulis untuk mengetahui lebih lanjut mengenai gambaran fungsi kognitif pada pasien pasca stroke.

\section{METODE PENELITIAN}

Penelitian ini dilakukan dalam bentuk literature review. Pencarian literatur dilakukan menggunakan tiga database yaitu Goggle Scholar, Pubmed, dan Clinical Key. Dalam pencarian menggunakan database Pubmed dan ClinicalKey digunakan filter rentang waktu dari tahun 2016-2020 dengan kata kunci cognitive impairment, cognitive decline, post-stroke, dan MoCA, sedangkan dalam pencarian menggunakan database Google Cendekia/Google Scholar digunakan fiter rentang waktu dari tahun 2016-2020 dengan kata kunci penurunan fungsi kognitif, pasca stroke, dan MoCA. Tabel 1 memperlihatkan kriteria inklusi dan eksklusi untuk penelitian ini.

Tabel 1. Kriteria inklusi dan eksklusi dalam penelitian ini

\begin{tabular}{|c|c|c|}
\hline Kriteria & Inklusi & Eksklusi \\
\hline Population & $\begin{array}{l}\text { Pasien dengan riwayat penyakit } \\
\text { stroke. }\end{array}$ & $\begin{array}{l}\text { Pasien yang mengidap penyakit } \\
\text { neurodegenerative. }\end{array}$ \\
\hline Instrument & MoCA / Ina-MoCA, TMT A dan B & MMSE dan CDT \\
\hline Comparation & - & - \\
\hline Outcome & $\begin{array}{l}\text { Gambaran fungsi kognitif pasien } \\
\text { pasca stroke. }\end{array}$ & 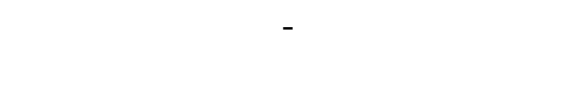 \\
\hline Study design & $\begin{array}{l}\text { Cross sectional, cohort, hospital- } \\
\text { based, tersedia full text maupun } \\
\text { jurnal yang dipublikasi }\end{array}$ & $\begin{array}{l}\text { Tidak tersedia full text maupun } \\
\text { jurnal yang dipublikasikan }\end{array}$ \\
\hline Tahun publikasi & $2016-2020$ & $<2016$ \\
\hline Bahasa & Indonesia dan Inggris & Selain bahasa Indonesia dan Inggris \\
\hline
\end{tabular}


68 Medical Scope Journal (MSJ), Volume 2, Nomor 2, Januari-Juni 2021, hlm. 66-72

HASIL PENELITIAN

Setelah melalui tahap seleksi studi didapatkan 10 literatur yang memenuhi kriteria inklusi dan eksklusi. Hasil utama literatur yang digunakan dalam penelitian ini dipaparkan dalam Tabel 2 dan Tabel 3.

Tabel 2. Hasil utama literatur yang digunakan dalam penelitian

\begin{tabular}{|c|c|c|c|}
\hline $\begin{array}{l}\text { Peneliti/ } \\
\text { Tahun }\end{array}$ & Judul & $\begin{array}{c}\text { Desain/ } \\
\text { Instrumen } \\
\text { penelitian }\end{array}$ & Rangkuman hasil \\
\hline Hanas, $2016^{8}$ & $\begin{array}{l}\text { Gambaran fungsi kognitif pada } \\
\text { pasien pasca stroke di } \\
\text { Poliklinik Saraf RSUD Arifin } \\
\text { Achmad Provinsi Riau }\end{array}$ & $\begin{array}{l}\text { Cross sectional/ } \\
\text { Ina-MoCA }\end{array}$ & $\begin{array}{l}\text { Terdapat } 38(92,68 \%) \text { pasien pasca } \\
\text { stroke dengan gangguan fungsi kognitif } \\
\text { dari } 41 \text { pasien yang menjadi sampel. } \\
\text { Gangguan kognitif lebih banyak terjadi } \\
\text { pada kelompok berjenis kelamin laki- } \\
\text { laki }(65,85 \%) \text {, berusia di atas } 65 \text { tahun } \\
(34,14 \%), \text { lama pendidikan di bawah } 12 \\
\text { tahun }(56,1 \%) \text {, jenis stroke iskemik } \\
(78,05 \%) \text {, dengan onset stroke di atas } 6 \\
\text { bulan }(75,61 \%)\end{array}$ \\
\hline $\begin{array}{l}\text { Windani, } \\
2016^{10}\end{array}$ & $\begin{array}{l}\text { Gambaran fungsi kognitif pada } \\
\text { pasien stroke di RSUP. Haji } \\
\text { Adam Malik Medan }\end{array}$ & $\begin{array}{l}\text { Cross sectional/ } \\
\text { Ina-MoCA }\end{array}$ & $\begin{array}{l}\text { Semua sampel mengalami penurunan } \\
\text { fungsi kognitif (62 sampel). } 62 \text { orang } \\
(100 \%) \text { mengalami gangguan pada do- } \\
\text { main visuospasial, bahasa, dan abstraksi } \\
\text { diikuti domain atensi } 58 \text { orang }(93,55 \%) \text {, } \\
\text { delayed recall } 53 \text { orang }(85,48 \%) \text {, orien- } \\
\text { tasi } 34 \text { orang }(54,84 \%) \text {, dan penamaan } 11 \\
\text { orang }(17,74 \%) \text {. Gangguan kognitif lebih } \\
\text { banyak terjadi pada pasien laki-laki } \\
(58 \%) \text {, kelompok usia } 41-60 \text { tahun } \\
(70 \%) \text {, stroke iskemik }(81 \%) \text {, lesi hemis- } \\
\text { fer kiri (64,5\%), jenjang pendidikan } \\
\text { SMA (42\%) dan memiliki risiko DM } \\
\text { atau hipertensi (82\%).Click or tap here } \\
\text { to enter text. }\end{array}$ \\
\hline Nijsse, $2016^{11}$ & $\begin{array}{l}\text { Temporal evolution of } \\
\text { poststroke cognitive } \\
\text { impairment } \\
\text { using the montreal cognitive } \\
\text { assessment }\end{array}$ & $\begin{array}{l}\text { Longitudinal } \\
\text { cohort study/ } \\
\text { MoCA }\end{array}$ & $\begin{array}{l}\text { Dari } 324 \text { pasien pasca stroke, } 215 \\
(66,36 \%) \text { di antaranya mengalami gang- } \\
\text { guan kognitif } 2 \text { bulan pasca stroke. Hasil } \\
\text { perhitungan rerata skor setiap domain } \\
\text { fungsi kognitif menemukan rerata skor } \\
\text { dari yang terendah sampai yang tertinggi } \\
\text { berturut-turut domain abstraksi diikuti, } \\
\text { memori, bahasa, visuospasial/eksekutif, } \\
\text { atensi, penamaan, dan orientasi. Gang- } \\
\text { guan kognitif lebih banyak terjadi pada } \\
\text { pasien berjenis kelamin laki-laki } \\
(62,79 \%) \text {, kelompok usia lebih dari } 65 \\
\text { tahun }(61,39 \%) \text {, dengan tingkat pendi- } \\
\text { dikan yang rendah }(80,93 \%) \text {. }\end{array}$ \\
\hline Totting, $2017^{12}$ & $\begin{array}{l}\text { Hubungan diabetes mellitus } \\
\text { dengan gangguan fungsi } \\
\text { kognitif post stroke iskemik di } \\
\text { Rumah Sakit Bethesda }\end{array}$ & $\begin{array}{l}\text { Cross sectional/ } \\
\text { MoCA }\end{array}$ & $\begin{array}{l}\text { Ditemukan pasien pasca stroke dengan } \\
\text { gangguan kognitif sebanyak } 75 \text { orang } \\
(68,18 \%) \text { dari } 110 \text { pasien. Gangguan } \\
\text { kognitif lebih banyak terjadi pada pasien } \\
\text { berjenis kelamin laki-laki ( } 68 \%) \text {, tingkat } \\
\text { pendidikan di bawah atau sama dengan } \\
12 \text { tahun }(61,33 \%) \text {, dan memiliki riwayat } \\
\text { hipertensi }(70,66 \%) \text {. Tidak ada hubung- } \\
\text { an antara DM dengan gangguan fungsi } \\
\text { kognitif pada pasien post stroke } \\
(p=0,334) \text {. }\end{array}$ \\
\hline
\end{tabular}




\begin{tabular}{|c|c|c|c|}
\hline Laksono, $2019^{5}$ & $\begin{array}{l}\text { Profil gangguan fungsi kognitif } \\
\text { pada pasien pasca stroke } \\
\text { iskemik di RSUP Sanglah } \\
\text { Denpasar Bali, Indonesia } \\
\text { periode } 2019\end{array}$ & $\begin{array}{l}\text { Cross sectional/ } \\
\text { Ina-MoCA }\end{array}$ & $\begin{array}{l}\text { Terdapat } 21 \text { pasien pasca stroke } \\
(80,76 \%) \text { dengan gangguan kognitif dari } \\
26 \text { sampel pasien. Domain yang paling } \\
\text { banyak terganggu adalah memori } 26 \\
\text { orang }(100 \%) \text {, diikuti atensi } 25 \text { orang } \\
(96,15 \%) \text {, bahasa } 18 \text { orang }(69,23 \%) \text {, } \\
\text { eksekutif } 11 \text { orang }(42,30 \%) \text {, dan visuo- } \\
\text { spasial } 7 \text { orang }(26,92 \%) \text {. Gangguan } \\
\text { kognitif terjadi lebih banyak pada } \\
\text { kelompok pasien berjenis kelamin laki- } \\
\text { laki }(66,67 \%) \text {, kelompok usia } 41-50 \\
\text { tahun }(42,85 \%) \text {, dengan jenjang pendi- } \\
\text { dikan terakhir SMP }(27 \%) \text {. }\end{array}$ \\
\hline Marlia, $2019^{13}$ & $\begin{array}{l}\text { Karakteristik gangguan } \\
\text { kognitif pada pasien rawat inap } \\
\text { neurologi di RSUD dr. Zainoel } \\
\text { Abidin Banda Aceh }\end{array}$ & $\begin{array}{l}\text { Cross sectional/ } \\
\text { Ina-MoCA }\end{array}$ & $\begin{array}{l}\text { Ditemukan } 36(97,29 \%) \text { dari } 37 \text { pasien } \\
\text { dengan riwayat stroke mengalami } \\
\text { gangguan kognitif. Domain yang paling } \\
\text { banyak terganggu ialah visuospasial dan } \\
\text { eksekutif } 35 \text { orang }(94,59 \%) \text { diikuti do- } \\
\text { main memori } 33 \text { orang }(89,19 \%) \text {, atensi } \\
31 \text { orang }(83,79 \%) \text {, bahasa } 31 \text { orang } \\
(83,79 \%) \text {, abstraksi } 28 \text { orang }(75,68 \%) \text {, } \\
\text { orientasi } 23 \text { orang }(62,16 \%) \text {, dan pena- } \\
\text { maan } 18 \text { orang }(48,65 \%) \text {. }\end{array}$ \\
\hline $\begin{array}{l}\text { Chaurasia, } \\
2019^{14}\end{array}$ & $\begin{array}{l}\text { Poststroke cognitive decline: a } \\
\text { longitudinal study from a } \\
\text { tertiary care center }\end{array}$ & $\begin{array}{l}\text { Prospective, } \\
\text { hospital based } \\
\text { study/ MoCA }\end{array}$ & $\begin{array}{l}126(67,02 \%) \text { pasien mengalami } \\
\text { gangguan fungsi kognitif dari } 188 \text { pasien } \\
\text { yang difollow-up } 3 \text { bulan pasca stroke. } \\
\text { Gangguan kognitif banyak terjadi pada } \\
\text { laki-laki }(73,01 \%) \text {, kelompok usia di atas } \\
60 \text { tahun }(67,46 \%) \text {, jenjang pendidikan } \\
\text { primary }(68,25 \%) \text {, stroke iskemik } \\
(60,31 \%), \quad \text { kelompok sosioekonomi } \\
\text { menengah }(61,90 \%) .{ }^{14}\end{array}$ \\
\hline $\begin{array}{l}\text { Ramadhani, } \\
2020^{15}\end{array}$ & $\begin{array}{l}\text { Hubungan stroke iskemik } \\
\text { dengan gangguan fungsi } \\
\text { kognitif di RS Universitas } \\
\text { Sumatera Utara }\end{array}$ & $\begin{array}{l}\text { Cross sectional/ } \\
\text { Ina-MoCA }\end{array}$ & $\begin{array}{l}\text { Dari } 24 \text { pasien pasca stroke, ditemukan } \\
12(50 \%) \text { pasien mengalami gangguan } \\
\text { kognitif. Dari } 12 \text { pasien tersebut ditemu- } \\
\text { kan gangguan kognitif lebih banyak } \\
\text { terjadi pada pasien laki-laki }(58,33 \%) \text {, } \\
\text { kelompok usia lebih atau sama dengan } \\
60 \text { tahun }(58,33 \%) \text {, dengan lama pendi- } \\
\text { dikan di bawah } 12 \text { tahun }(83,33 \%) \text {. Dida- } \\
\text { patkan adanya hubungan antara usia } \\
\text { ( } p=0,035) \text { dan lama pendidikan }(p=0,013) \\
\text { dengan gangguan fungsi kognitif pasien } \\
\text { post stroke serta tidak adanya hubungan } \\
\text { dengan jenis kelamin }(p=0,673) \text {. }\end{array}$ \\
\hline $\begin{array}{l}\text { Rahmawati, } \\
2020^{16}\end{array}$ & $\begin{array}{l}\text { Gambaran hipertensi dengan } \\
\text { kejadian demensia vaskular } \\
\text { pada pasien stroke non } \\
\text { hemoragik di Poli Saraf RSUD } \\
\text { Sultan Syarif Mohamad } \\
\text { Alkadrie Pontianak }\end{array}$ & $\begin{array}{l}\text { Cross sectional/ } \\
\text { Ina-MoCA }\end{array}$ & $\begin{array}{l}\text { Ditemukan } 55(96,49 \%) \text { pasien menga- } \\
\text { lami gangguan fungsi kognitif dari } 57 \\
\text { pasien yang menjadi sampel dengan } 34 \\
\text { pasien mengalami gangguan fungsi } \\
\text { kognitif sedang }(59,68 \%) \text {. }\end{array}$ \\
\hline $\begin{array}{l}\text { Yuwanda, } \\
2020^{17}\end{array}$ & $\begin{array}{l}\text { Hubungan antara lokasi stroke } \\
\text { dengan gangguan kognitif pada } \\
\text { penderita stroke Di RSUP } \\
\text { Sanglah Denpasar }\end{array}$ & $\begin{array}{l}\text { Cross sectional/ } \\
\text { Ina-MoCA }\end{array}$ & $\begin{array}{l}\text { Didapatkan diantara } 80 \text { sampel terdapat } \\
60(75 \%) \text { pasien dengan gangguan fungsi } \\
\text { kognitif. Gangguan kognitif lebih } \\
\text { banyak terjadi pada pasien dengan lokasi } \\
\text { stroke hemisfer kiri yaitu sebanyak } 32 \\
(53,33 \%) \text { pasien. Ditemukan adanya } \\
\text { hubungan antara lokasi stroke dengan } \\
\text { gangguan kognitif pada pasien post } \\
\text { stroke }(p=0,006) \text {. }\end{array}$ \\
\hline
\end{tabular}


Tabel 3. Persentase pasien pasca stroke yang mengalami gangguan kognitif dari masingmasing literatur

\begin{tabular}{ccc}
\hline Peneliti /Tahun & $\begin{array}{c}\text { Gangguan } \\
\text { kognitif } \\
(\mathbf{\%})\end{array}$ & $\begin{array}{c}\text { Normal } \\
(\%)\end{array}$ \\
\hline Hanas et al, 2016 & 93 & 7 \\
Windani, 2016 $^{10}$ & 100 & 0 \\
Nijsse et al, 2016 & 66 & 34 \\
Totting et al, 2017 & 68 & 32 \\
Laksono et al, 20195 & 81 & 19 \\
Marlia 201913 & 97 & 3 \\
Chaurasia et al, & 67 & 33 \\
201914 & & \\
Ramadhani dan & 50 & 50 \\
Hutagalung, 2020 & & \\
Rahmawati et al, & 96 & 4 \\
202016 & & \\
Yuwanda et al, & 75 & 25 \\
2020 & & \\
\hline
\end{tabular}

\section{BAHASAN}

Pada penelitian ini didapatkan banyak pasien pasca stroke yang mengalami gangguan fungsi kognitif. Sembilan literatur melaporkan jumlah pasien stroke dengan gangguan kognitif lebih dari $50 \%$ pasien yang menjadi sampel masing-masing penelitian. Stroke terjadi akibat adanya oklusi pada lumen arteri serebral dan pecahnya pembuluh darah pada stroke yang mengakibatkan menurunnya jumlah darah yang mengalir ke bagian otak tertentu, dan bermanifestasi dalam bentuk defisit neurologik tergantung lokasi anatomi otak yang terganggu, salah satunya fungsi kognitif. ${ }^{8}$

Hasil penelitian ini mendapatkan empat literatur yang membahas mengenai domain yang paling banyak terganggu pada pasien pasca stroke. Gambaran gangguan domain fungsi kognitif pasien pasca stroke berbeda pada keempat literatur yang dikaji. Pada penelitian yang dilakukan oleh Windani ${ }^{10}$ dilaporkan bahwa domain yang paling banyak terganggu ialah visuospasial/ eksekutif, bahasa, dan abstraksi, dengan semua sampel (100\%) mengalamai gangguan pada domain tersebut, diikuti domain atensi $(93,55 \%)$. Nijsse et al $^{11}$ mendapatkan tiga domain yang memiliki rerata skor paling rendah yaitu abstrak, memori, dan bahasa sedangkan Laksono et $\mathrm{al}^{5}$ mendapatkan domain fungsi kognitif yang paling sering terganggu ialah memori (100\%) dan atensi $(96,15 \%)$. Berbeda halnya dengan Marlia ${ }^{13}$ yang justru mendapatkan fungsi visuospasial/eksekutif $(94,59 \%)$ yang paling banyak terganggu pada pasien pasca stroke. Perbedaan hasil yang terjadi dapat disebabkan karena perbedaan demografis sampel pada masing-masing literatur. Banyak hal yang dapat memengaruhi manifestasi gangguan kognitif, salah satunya letak lesi. Lesi pada hemisfer kanan akan menimbulkan gangguan fungsi visuospasial, visuomotor, memori visual, dan koordinasi motorik, sedangkan lesi pada hemisfer kiri menimbulkan gangguan kemampuan berbahasa, membaca, menulis, menghitung, memori verbal, dan gerakan motorik terampil. Dari keempat literatur yang membahas mengenai domain fungsi kognitif pada pasien stroke dapat disimpulkan bahwa domain yang paling sering terganggu ialah visuospasial/ eksekutif, memori, bahasa, abstrak dan atensi. Domain penamaan dan orientasi juga dapat mengalami gangguan pada pasien pasca stroke dengan angka kejadian yang rendah. ${ }^{5,10,11,13}$

Penelitian yang dilakukan oleh Hanas et al, ${ }^{8}$ Windani, ${ }^{10}$ Nijsse et al, ${ }^{11}$ Totting et al, ${ }^{12}$ Laksono et al, ${ }^{5}$ Chaurasia et al, ${ }^{14}$ serta Ramadhani dan Hutagalung ${ }^{15}$ medapatkan bahwa jumlah pasien pasca stroke yang mengalami penurunan fungsi kognitif lebih banyak pada laki-laki dibandingkan perempuan. Hal ini terjadi akibat adanya perbedaan kinerja fungsi otak antara perempuan dan laki-laki. Gangguan kognitif lebih banyak ditemukan pada laki-laki. Juga disebabkan oleh karena otak perempuan lebih mudah beradaptasi dengan normal aging sehingga lebih lambat mengalami proses penurunan fungsi kognitif. ${ }^{18}$ Dengan menggunakan uji chi square dalam penelitian yang dilakukan oleh Ramadhani dan Hutagalung, ${ }^{15}$ didapatkan tidak adanya hubungan antara jenis kelamin dengan gangguan fungsi kognitif pada pasien pasca stroke dengan nilai $\mathrm{p}=0,673(\mathrm{p}<0,05)$.

Penelitian yang dilakukan oleh Hanas et 
al, ${ }^{8}$ Windani, ${ }^{10}$ Nijsse et al, ${ }^{11}$ Chaurasia et $\mathrm{al}^{14}$ serta Ramadhani dan Hutagalung ${ }^{15}$ menunjukkan bahwa pasien pasca stroke yang mengalami gangguan kognitif lebih banyak terjadi pada kelompok usia di atas atau sama dengan 60 tahun. Bahkan penelitian yang dilakukan oleh Windani ${ }^{10}$ dan Laksono et $\mathrm{al}^{5}$ menyatakan bahwa gangguan kognitif banyak terjadi pada kelompok usia 41-50 tahun. Pertambahan usia sangat berpengaruh dengan terjadinya penurunan fungsi kognitif disebabkan karena konsep normal aging yang berpengaruh secara langsung pada penurunan fungsi kognitif. Menurunnya fungsi otak mengikuti pertambahan usia pasien akibat terjadinya atrofi pada sel otak. ${ }^{8}$ Ramadhani dan Hutagalung $^{15}$ juga melaporkan adanya hubungan antara usia dengan penurunan fungsi kognitif pada pasien pasca stroke dengan nilai $\mathrm{p}=0,035(\mathrm{p}<0,05)$.

Gangguan kognitif pada pasien pasca stroke banyak terjadi pada pasien dengan jenjang pendidikan rendah. Penelitian yang dilakukan oleh Hanas et al, ${ }^{8}$ Totting et al, ${ }^{12}$ serta Rhamadani dan Hutagalung ${ }^{15}$ menunjukkan bahwa gangguan kognitif pada pasien pasca stroke banyak terjadi pada pasien dengan jenjang pendidikan di bawah 12 tahun. Windani ${ }^{10}$ melaporkan angka kejadian yang tinggi pada pasien dengan jenjang pendidikan tingkat SMA. Laksono et $\mathrm{al}^{5}$ bahkan mendapatkan angka kejadian yang tinggi pada pasien dengan pendidikan terakhir tingkat SMP. Hal ini disebabkan karena fungsi kognitif pasien dengan jenjang pendidikan yang tinggi jauh lebih baik daripada pasien dengan jenjang pendidikan yang rendah. Pengalaman dan lamanya pendidikan melatih pasien dalam melaksanakan fungsi kognitif seperti pemecahan masalah dan berfikir efektif. ${ }^{5}$ Penelitian yang dilakukan oleh Ramadhani dan Hutagalung $^{15}$ menunjukkan adanya hubungan antara jenjang pendidikan dengan penurunan fungsi kognitif pada pasien pasca stroke dengan nilai $\mathrm{p}=0,013(\mathrm{p}<0,05)$.

Hanas et $\mathrm{al}^{8}$ mendapatkan adanya hubungan antara lokasi lesi dengan penurunan fungsi kognitif pada pasien pasca stroke dengan nilai $\mathrm{p}=0,006(\mathrm{p}<0,05)$. Selain itu, penelitian oleh Windani ${ }^{10}$ dan Yuwanda et $\mathrm{al}^{17}$ mendapatkan bahwa adanya gangguan kognitif pada pasien stroke dengan lesi hemisfer kiri lebih banyak daripada lesi hemisfer kanan. Hanas et al, ${ }^{8}$ Windani, ${ }^{10}$ dan Chaurasia et $\mathrm{al}^{14}$ melaporkan bahwa gangguan kognitif lebih banyak terjadi pada pasien pasca stroke iskemik daripada yang hemoragik.

Totting et al ${ }^{12}$ melaporkan bahwa pasien dengan riwayat hipertensi memiliki angka kejadian penurunan fungsi kognitif pasca stroke yang lebih tinggi daripada yang tidak memiliki riwayat hipertensi. Selain itu, didapatkan juga tidak adanya hubungan antara diabetes melitus dengan penurunan fungsi kognitif pada pasien pasca stroke dengan nilai $\mathrm{p}=0,334(\mathrm{p}<0,05)$.

\section{SIMPULAN}

Terdapat hubungan antara penurunan fungsi kognitif dengan lokasi lesi, usia, dan jenjang pendidikan namun tidak terdapat hubungan dengan jenis kelamin dan diabetes melitus. Penurunan fungsi kognitif terbanyak pada domain visuospasial/eksekutif, memori, bahasa, atensi dan abstrak. Tidak terdapat hubungan antara jenis kelamin dan diabetes mellitus dengan penurunan fungsi kognitif pasca stroke.

Perlu dilakukan penelitian lebih lanjut dengan metode lain dan sampel yang lebih banyak agar mendapatkan hasil yang lebih akurat.

\section{Konflik Kepentingan}

Penulis menyatakan tidak terdapat konflik kepentingan dalam studi ini.

\section{DAFTAR PUSTAKA}

1. Sacco RL, Kasner SE, Broderick JP, Caplan LR, Connors JJB, Culebras A, et al. An updated definition of stroke for the 21st century: a statement for healthcare professionals from the American heart association/American stroke association. Stroke. 2013;44(7):2064-89. Doi:10.1161/STR.0b013e318296aeca

2. World Stroke Organization. Global Stroke Fact Sheet. Published online 2016. Available from: https://www.world-stroke.org/ assets/downloads/WSO_Global_Stroke 
72 Medical Scope Journal (MSJ), Volume 2, Nomor 2, Januari-Juni 2021, hlm. 66-72

Fact_Sheet.pdf

3. Kemenkes RI. Infodantin Stroke Kemenkes RI 2019. Published online 2019. Available from: https://pusdatin.kemkes.go.id/ article/view/20031000003/infodatinstroke.html

4. Wibowo MM, Karema W, Pertiwi JM. Gambaran fungsi kognitif dengan InaMoCA dan MMSE pada penderita poststroke di Poliklinik Saraf BLU RSUP Kandou Manado November - Desember 2014. e-CliniC. 2015;3(3):3-6. Doi:10. 35790/ecl.3.3.2015.9421.

5. Laksono BA, Widyastuti K, Trisnawati SY. Profil gangguan fungsi kognitif pada pasien pasca stroke iskemik di RSUP Sanglah Denpasar Bali, Indonesia periode 2019. Intisari Sains Medis. 2019;10(3): 698-701. Doi:10.15562/ ism.v10i3.4633/8. 52385.pdf

6. Vascular Dementia: background, pathophysiology, epidemiology. [cited 2020 Nov 9]. Available from:https://emedicine.med scape.com/article/292105-overview.

7. Kumalasari AN, Rahmayani F, Hamidi S. Diagnosis dan Pencegahan Perburukan Demensia Vaskular pada Pasien Pasca Stroke. Medula. 2018;8(1):25-32.

8. Hanas M, Lestari E, Asni EK. Gambaran fungsi kognitif pada pasien pasca stroke di Poliklinik Saraf RSUD Arifin Achmad Provinsi Riau. Journal of Chemical Information and Modeling. 2019;53(9): 1689-99. Doi: $10.1017 / \mathrm{CBO} 97811074$ 15324.004 .

9. Paparang TN, Mahama CN, Ngantung DJ. Gambaran fungsi kognitif pada pasien rawat jalan dengan riwayat stroke di Poliklinik Saraf RSUP Prof. Dr. R.D. Kandou Manado. Jurnal Biomedik. 2013;5(1):2013.

10. Windani M. Gambaran fungsi kognitif pada pasien stroke di RSUP Haji Adam Malik Medan. Repositori Institusi USU. Available from: http://repositori.usu. ac.id/handle/123456789/19788.

11. Nijsse B, Visser-Meily JMA, van Mierlo ML, Post MWM, de Kort PLM, van Heugten
CM. Temporal evolution of poststroke cognitive impairment using the Montreal cognitive assessment. Stroke. 2017;48(1):98-104. Doi: 10.1161/ STROKEAHA.116.014168.

12. Totting S, Pinzon RT, Widiasmoko B. Hubungan diabetes melitus dengan gangguan fungsi kognitif post stroke iskemik di Rumah Sakit Bethesda. Jurnal Kesehatan Andalas. 2018;6(3):647. Doi: 10.25077/jka.v6i3.752.

13. Marlia I. Karakteristik gangguan kognitif pada pasien rawat inap neurologi di RSUD dr. Zainoel Abidin Banda Aceh. Medicus Darussalam. 2019;1(2):1-7.

14. Chaurasia RN, Sharma J, Pathak A, Mishra VN, Joshi D. Poststroke cognitive decline: a longitudinal study from a tertiary care center. Journal of Neurosciences in Rural Practice. 2019;10(3): 459-64. Doi:10.1055/s-0039-1697872.

15. Ramadhani SS, Hutagalung HS. Hubungan stroke iskemik dengan gangguan fungsi kognitif di RS Universitas Sumatera Utara. SCRIPTA SCORE Scientific Medical Journal. 2020;2(1):20-27. Doi:10.32734/scripta.v2i1.3373.

16. Rahmawati WT, An A, Raharjo W. Gambaran hipertensi dengan kejadian demensia vaskular pada pasien stroke non hemoragik di Poli Saraf RSUD Sultan Syarif Mohamad Alkadrie Pontianak. Jurnal Kedokteran dan Kesehatan: Publikasi Ilmiah Fakultas Kedokteran Universitas Sriwijaya. 2020;7(2):131-7.

17. Yuwanda K, Putri Laksmidewi AAA, Widyastuti K. Korelasi antara lokasi stroke dengan gangguan kognitif pada penderita stroke di RSUP Sanglah Denpasar. Callosum Neurology. 2020;3(1):1-5. Doi:10.29342/cnj.v3i1.101.

18. Goldman B. How men's and women's brains are different. Stanford Medicine. Published 2017. [cited 2020 Dec 6]. Available from: https://stanmed. stanford.edu/2017spring/how-mensand-womens-brains-are-different.html. 